University of Warwick institutional repository: http://go.warwick.ac.uk/wrap

This paper is made available online in accordance with publisher policies.

Please scroll down to view the document itself. Please refer to the repository record for this item and our policy information available from the repository home page for further information.

To see the final version of this paper please visit the publisher's website. Access to the published version may require a subscription.

Author(s): Michael Waterson \& Fabian Bergess- Sennou

Article Title: Private label products as experience goods

Year of publication: 2005

Link to published version: http://www.bepress.com/jafio/vol3/iss2/art9/ 


\section{PRIVATE LABEL PRODUCTS AS EXPERIENCE GOODS ${ }^{\#}$}

\section{Fabian BERGÈS-SENNOU ${ }^{*}$ \& Michael WATERSON ${ }^{* *}$}

$$
\text { July } 2003
$$

\section{Abstract}

Food retailing has become more concentrated and private label goods have spread over the last 40 years.

Using a two-stage model in which consumers become informed about the quality of the good only in period 2, we examine what determines the presence or absence of private label experience goods in supermarkets.

Our most novel result is that in the case of products purchased infrequently, producing a reputable private label is not sustainable.

Retailer bargaining power increases the likelihood of a private label good being produced. Evidence from France is consistent with the main propositions.

JEL Classification : L11, L14, D21, D42.

Keywords: Private label, experience good, new good.

\footnotetext{
\# We would particularly like to thank Vincent Réquillart, Patrick Rey and the Warwick IO seminar participants for their comments and constructive remarks.

* Corresponding author : INRA-ESR, Chemin de Borde Rouge, BP 27, F-31326 Castanet-Tolosan Cédex - FRANCE. Mail: Fabian.Berges@toulouse.inra.fr

** University of Warwick, Department of Economics, Coventry, CV4 7AL - UK. Mail: Michael.Waterson@warwick.ac.uk
} 


\section{Introduction}

Two major features of the retailing industry evolution in Europe over the last 40 years are increased concentration and the spread of private label products. Successive mergers between distributors have led to concentrated retailing markets. For example, in France, the five biggest retailers accounted for more than $65 \%$ of the food retailing in 2001, and in the United Kingdom, the CR5 was $56 \%$ in $1996 .^{1}$ In addition to this increase in concentration in the food retailing industry, distributors have successfully launched private labels (also named store brands or own brands). In the UK, the average market share of private label was about $41 \%$ in volume for 2002, whereas in France it was $24 \%{ }^{2}$ One consequence of these dual trends in the food retailing industry is to increase retailers' bargaining power vis-à-vis the upstream sector.

However, looking more closely at the UK private label statistics, some products such as Beer, Lager \& Cider $(14 \%)$ or Baby Food $(4.3 \%)$ show low penetration rates. In explaining such low penetration rates, the lack of confidence in the product (or in the retailer's brand relative to the national brand) is relevant - see Table 1, as described in Shapiro (1993).

This suggests clearly that the characteristics of the good are important for the retailer's decision whether or not to introduce a private label. In the food sector, most goods can be considered to be experience goods $^{3}$, in the sense of Nelson (1970); that is, sampling the good destroys it. This aspect of food purchasing has not been taken into account by the classical economic analysis of private labels where the store brand is always considered to be a search good. ${ }^{4}$ In such articles, for example Mills (1995) or Bomtems, Monier and Réquillart (1999), private label quality serves to discriminate final consumers demand and increases the competition between private label and branded products enabling the retailer to get input price concessions. However, the experience good characteristic of the private label provides an additional strategy to the retailer when considering the introduction of a store brand. As pointed out by Shapiro (1982 and 1983), with an experience good the retailer can cheat for some period on the quality sold to consumers, since they will only discover the true quality after some lag. The retailer therefore has an incentive to benefit from this information imperfection by milking the consumer.

\footnotetext{
${ }^{1}$ See Clarke et al.. (2002) for a description of European food retailing.

2 PLMA's 2002 International Private Label Yearbook, prepared by AC Nielsen.

${ }^{3}$ Some of them may be credence goods where quality is never ascertained. Examples might include goods with health risks like meat for instance. Nevertheless, a credence good can be thought as an experience good where the lag between consumption and quality revelation tends to be infinite.

${ }^{4}$ For an economic survey of private label, see Bergès-Sennou, Bomtems and Réquillart (2003).
} 


\begin{tabular}{|c|c|c|c|c|}
\hline Average & $41 \%$ & $\begin{array}{l}\text { Freq. Of } \\
\text { Purchase }\end{array}$ & $\begin{array}{l}\text { Brand } \\
\text { Loyalty } \\
\text { Factor }\end{array}$ & $\begin{array}{c}\text { PL market share } \\
\text { under the } \\
\text { average }\end{array}$ \\
\hline Health and Beauty & $24.40 \%$ & 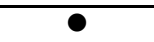 & 000 & $\bullet$ \\
\hline Household & $30.40 \%$ & 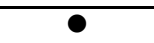 & 000 & $\bullet$ \\
\hline Spirits and Liqueurs & $25.80 \%$ & $\bullet$ & $\bullet \bullet \bullet$ & $\bullet$ \\
\hline Hot Beverages & $27.20 \%$ & $\bullet$ & $\bullet \bullet$ & $\bullet$ \\
\hline Paper Products & $19.40 \%$ & $\bullet$ & $\bullet$ & $\bullet$ \\
\hline Dry Grocery & $43.40 \%$ & $\bullet$ & $\bullet$ & \\
\hline Beer, Lager and Cider & $14 \%$ & 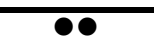 & 000 & $\bullet$ \\
\hline Light Wines & $46.90 \%$ & $\bullet \bullet$ & $\bullet \bullet$ & \\
\hline Soft Drinks & $47.10 \%$ & 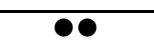 & $\boldsymbol{\theta \bullet}$ & \\
\hline Delicatessen & $79.60 \%$ & $\bullet \bullet$ & $\bullet$ & \\
\hline Frozen & $46.30 \%$ & 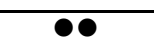 & $\bullet$ & \\
\hline Confectionery & $18.80 \%$ & $\bullet \bullet \bullet$ & $\bullet \bullet \bullet$ & $\bullet$ \\
\hline Pet Food and Care & $16.30 \%$ & $\bullet \bullet \bullet$ & $\bullet \bullet \bullet$ & $\bullet$ \\
\hline Biscuits & $41.40 \%$ & $\bullet \bullet \bullet$ & $\bullet$ & \\
\hline Bakery & $62.90 \%$ & $\bullet \bullet \bullet$ & $\bullet$ & \\
\hline Dairy & $67 \%$ & $\ddot{000}$ & $\bullet$ & \\
\hline Fruit & $74.50 \%$ & $\bullet \bullet \bullet$ & $\bullet$ & \\
\hline Meat, Fish and Poultry & $88.50 \%$ & $\ddot{000}$ & $\bullet$ & \\
\hline Vegetables & $58.40 \%$ & 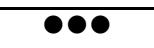 & $\bullet$ & \\
\hline
\end{tabular}

Table 1: Private label penetration in UK (AC/Nielsen and PLMA for the figures).

The objective of this paper is to examine what determines whether a reputable private label will be produced, focusing on frequency of purchase and retailer bargaining power, and hence to see if there is a rationale for the retailer to milk its reputation on the store brand.

We first find that for products with low purchase frequency (or products where the lag between consumption and quality assertion is high), a reputable private label is not sustainable. However, there is not a monotonicity of the introduction decision with respect to the private label production cost. In other words, a decrease in the cost of the own good can increase the incentives for the retailer to milk as quality chosen becomes closer to the one of the branded product and thus foregone future discrimination profits when milking are lower.

Second, when considering the retailer's bargaining power in the analysis, we find that an increase in the distributor's bargaining power can help him to sell a reputable private label. However, for low-frequency purchase goods, or credence goods, whatever his bargaining power, a private label is never reputable enough for consumer because the incentives to milk are always higher than to maintain reputation.

This analysis casts some light on why reputation is an important characteristic in the economic analysis of private labels, and thus why branded products do so well in specific areas where brand name is really important for consumers, but not in other areas.

In the next section, we describe the framework of the model (consumer demand, retailer's options) and solve the three possible equilibria. The subsequent section derives the retailer's choice on the reputation issue. The fourth section incorporates retailer bargaining power into the private label reputation analysis. Section five concludes. 


\section{The framework}

In order to analyse the reputation issue, we consider two goods sold by a retailer to consumers on the final market, one branded, the other private label. Demand is vertically differentiated. We first describe the consumer's preferences, then the retailer's options. This section ends with the computation of the three possible equilibria.

\subsection{Consumers' demand}

The retailer faces consumers differing in their willingness to pay for product quality. The consumer's utility when she buys a unit of good of quality $q$ at price $p$ is of Mussa-Rosen (1978) form:

$$
U(\theta, q)=\theta q-p \text { where } \theta \text { is the willingness to pay for quality }
$$

We also assume that $\theta \sim U[0,1]$.

When there is only one good, the consumer indifferent between consuming the good or not is characterised by $U\left(\theta_{0}, q\right)=0$, that is: $\theta_{0}(p, q)=\frac{p}{q}$. The retailer therefore faces demand:

$$
D(p, q)=1-\theta_{0}=1-\frac{p}{q}
$$

In the case where consumers are offered two goods, one is assumed to be of high quality $\bar{q}$ (and sold at price $\bar{p}$ ) whereas the other is of lower quality $\underline{q}$ (sold at $\underline{p}$ ). The consumer indifferent between buying the high and low quality good is characterised by $U(\tilde{\theta}, \bar{q})=U(\tilde{\theta}, \underline{q})$, that is: $\tilde{\theta}(p, q)=\frac{\bar{p}-\underline{p}}{\bar{q}-\underline{q}}$. There also exists a consumer indifferent between buying the low quality good and nothing. She has $\theta_{0}(p, q)=\frac{\underline{p}}{\underline{q}}$.

Thus demand for the high quality good is defined by:

$$
D_{\underline{q}}(p, q)=1-\tilde{\theta}(p, q)=1-\frac{\bar{p}-\underline{p}}{\bar{q}-\underline{q}}
$$

Similarly, demand for the low quality good is given by:

$$
D_{\bar{q}}(p, q)=\tilde{\theta}(p, q)-\theta_{0}(p, q)=\frac{\bar{p}-\underline{p}}{\bar{q}-\underline{q}}-\frac{\bar{p}}{\underline{q}}
$$

At the equilibrium both goods are sold as long as $\tilde{\theta}(p, q)<1$ and $\tilde{\theta}(p, q)>\theta_{0}(p, q)$. This gives two conditions on prices to be satisfied: 


$$
1>\tilde{\theta}(p, q) \Leftrightarrow \bar{p}-\underline{p}<\bar{q}-\underline{q} \text { and } \tilde{\theta}(p, q)>\theta_{0}(p, q) \Leftrightarrow \frac{\bar{p}}{\underline{p}}>\frac{\bar{q}}{\underline{q}}
$$

\subsection{The retailer's options}

The central goal of this paper is to analyse the retailer's incentive to introduce a new product where quality is chosen by the retailer: a private label. Since when considering experience goods dynamics matter, we must distinguish three periods in the game:

- The first period is prior to the introduction of the new good: the retailer is assumed to have been selling a well-established (national) brand for some time.

- The second period commences after the decision to introduce the new good has been made, and ends before consumers observe quality.

- The third period is the infinite horizon after consumers have observed quality and so have decided whether or not to buy the new product again.

So far as the national brand is concerned, its name, the advertising done by the producer and the fact it has been consumed for previous periods make its characteristics well known to consumers. The quality of the branded product is normalized to $q_{B}=1$.

In addition to this existing product, the retailer wishes to introduce its own brand product. However, because it is a new product, consumers will treat it as an experience good and will form prior beliefs on the quality chosen by the retailer. We give consumers' expectations the same structure as in Shapiro (1983). Consumers' beliefs are updated according to the rule $R_{t}=q_{t-1}$, where $R_{t}$ is the retailer's reputation at date $t$ and $q_{t-1}$ is the quality observed by consumers in the previous period. Moreover, this adjustment equation supposes that all consumers share information by communicating with each other. The quality of the private label is publicly disclosed in the model $^{5}$. Note that consumers differ only in their willingness to pay for quality, not on the quality level of the product once consumed. The adjustment equation reflects the fact that consumers do not observe private label quality prior to purchase. A direct consequence is that the retailer can milk, at least for one period, by providing lower quality than that expected by consumers. This possible cheating strategy is clearly due to the one period lag between observing quality and updating beliefs. In this paper, we look for the retailer's incentives to provide a reputable private label.

Because what happens before the introduction of the private label does not influence the future, only two periods are relevant in the framework. Period $t=1$ will denote the introduction of the new good, and period $t=2$ encompasses the remaining periods after the private label quality has

\footnotetext{
${ }^{5}$ One justification, given in Allen (1984), is consumers share information through publications like consumers' reports in magazines, market surveys or word-of-mouth reputation.
} 
been observed by consumers. The retailer's total profit can therefore be written as $\Pi=\pi_{1}+\Delta \pi_{2}$ where $\pi_{1}$ is the profit made in the first period and $\pi_{2}$ summarises all the profits made thereafter. The parameter $\Delta$ is the composite discount factor between period 1 and the remaining periods encompassed in period 2. ${ }^{6}$ The composite discount factor is important in capturing the difference between products. Indeed, for some products, the lag between the first purchase and any repurchase can be high (for example, Health and Beauty, Hot beverage, Household) whereas some other products are consumed more frequently (Dairy, Groceries). In our analysis, products with a low frequency of purchase are characterised by a low $\Delta$, and for frequently purchased products, the retailer faces a higher $\Delta .^{7}$ The national brand and the private label are purchased equally frequently so there is no need to consider a different discount factor across them.

\subsection{The three possible equilibria}

The technology faced by the national brand producer for the branded product leads to a unit cost of $c\left(q_{B}\right)=\frac{1}{2} q_{B}{ }^{2}$. Since we assumed $q_{B}=1$, the branded product unit cost is $1 / 2$. The private label manufacturer is assumed to face the same technology (quadratic unit cost function in quality), but may or may not be at a disadvantage relative to the national brand producer, as in Bontems, Monier and Réquillart (1999) or in Caprice (2000). Therefore, $c\left(q_{S}\right)=\frac{1}{2} c q_{S}{ }^{2}$ with $c>\frac{8}{9}$. We allow for a range of parameters for $c$ which encompass both a disadvantage and a slight advantage. We assume that the manufacturer makes zero mark-up on the private label wholesale price. This is a classic assumption found in Mills (1995) or in Bontems, Monier and Réquillart (1999).

We also assume that the contract between the national brand manufacturer and the retailer is a two-part tariff. It is well known that in the absence of competition downstream, the result of a two-part tariff contract will be to set the wholesale price at marginal cost, so $w_{B}=1 / 2$. For the moment, we suppose the retailer has all the bargaining power and makes a take-it or leave-it offer to the branded product manufacturer. The franchise fee thereby allows the distributor to capture the entire vertical surplus created from the national brand sale. ${ }^{9}$

${ }^{6}$ To be precise, the retailer profit should be given by $\Pi=\pi_{1}+\sum_{t=2}^{+\infty} \delta^{t} \pi_{t}$ where $\delta$ is the period discount factor. But $\pi_{t \geq 2}=\pi_{2}$ and $\sum_{t=2}^{+\infty} \delta^{t}=\frac{\delta}{1-\delta}$. Defining $\Delta=\frac{\delta}{1-\delta}$ allows the profit to be rewritten as: $\Pi=\pi_{1}+\Delta \pi_{2}$.

${ }^{7}$ The period discount factor can be written as $\delta=e^{-i T}$ where $i$ is the market interest rate and $T$ is the lag between periods. Therefore, as $T$ increases $\delta$ decreases, and so does $\Delta$. Note that for credence good, where quality is never ascertained, this translates by $T \rightarrow+\infty$, implying $\Delta \rightarrow 0$.

${ }^{8}$ One justification, given in Allen (1984), is consumers share information through publications like consumers' reports in magazines, market surveys or word-of-mouth reputation.

${ }^{9}$ For more explanation and results on a two-part tariff, see e.g. Tirole (1988). 
The first steady-state equilibrium consists in selling the national brand product to consumers for ever. Since we normalized the branded product quality to $q_{B}=1$, the retailer chooses the price $p_{B}$ maximizing:

$$
\Pi_{B}=\left(p_{B}-\frac{1}{2}\right) \cdot\left(1-p_{B}\right)+\Delta\left(p_{B}-\frac{1}{2}\right) \cdot\left(1-p_{B}\right)
$$

This leads to the following equilibrium price and profits:

$$
p_{B}^{*}=\frac{3}{4} \text { and } \Pi_{B}^{*}=\frac{1+\Delta}{16}
$$

The second possible equilibrium is for the retailer to sell the national brand product and to introduce its own private label good, incurring a fixed cost $F .{ }^{10}$ In this article, brand loyalty is not modelled explicitly. Although it is an important feature when considering the introduction of a new good, it can be taken into account in our framework in two ways. First, consumers do not perceive the national brand as an experience good. This means that the national brand is a well- established product and so its quality is known. Second, the fixed cost element is assumed to reflect the degree of difficulty the new product has in coping with the loyalty of the existing one. In other words, if the private label faces a very well established brand with loyal consumers, the cost in advertising and promotional campaigns should be higher. Therefore, in this framework, an increase in $F$ can be interpreted as an increase in the brand's loyalty.

We assume that the national brand is of higher quality than the private label one: $q_{B}>q_{S}{ }^{11}$ The retailer chooses the final prices for both products, but also the quality of its store brand. The program is thus:

$$
\operatorname{Max}_{\left\{\mathrm{p}_{\mathrm{B}}, \mathrm{ps}_{\mathrm{s}}, \mathrm{q}_{\mathrm{S}}\right\}}(1+\Delta) \cdot\left[\left(p_{B}-\frac{1}{2}\right)\left(1-\frac{p_{B}-p_{S}}{1-q_{S}}\right)+\left(p_{S}-\frac{1}{2} c q_{S}^{2}\right)\left(\frac{p_{B}-p_{S}}{1-q_{S}}-\frac{p_{S}}{q_{S}}\right)\right]-F
$$

The price solutions expressed in terms of private label quality are given by:

$$
p^{*}\left(q_{S}\right)=\frac{1}{4}\left(2+c q_{s}\right) q_{S} \text { and } p_{S}{ }^{*}=\frac{3}{4}
$$

This leads to an optimal private label quality of:

$$
q_{s}^{*}(c)=\frac{3}{4}-\frac{\sqrt{9 c-8}}{4 \sqrt{c}}
$$

Finally, the equilibrium prices and profit are:

$$
p_{S}^{*}(c)=\frac{1}{32}\left(8+9 c-\frac{(4+3 c) \sqrt{9 c-8}}{\sqrt{c}}\right) ; p_{B}^{*}=\frac{3}{4}
$$

\footnotetext{
${ }^{10}$ Such a fixed cost could be illustrated by necessary advertisement in-store for the new product and a promotional campaign.

${ }^{11}$ This is a classic assumption made in the economic literature on private label as in Mills (1995) or Bontems, Monier and Réquillart (1999). It seems to fit quite well with facts, since consumers tend to judge the private label product as inferior to the national brand one, or at least not superior. See Rao and Monroe (1989) or Richardson, Dick and Jain (1994) for consumers' blind tests on this issue.
} 


$$
\text { and } \Pi_{B+S}{ }^{*}=\frac{1}{128}(1+\Delta) \cdot\left(\sqrt{c}(9 c-8)^{\frac{3}{2}}-9 c(3 c-4)\right)-F
$$

Note that the conditions required in equation (5) are fulfilled so long as $c>\frac{8}{9}$.

The third possible equilibrium is for the retailer is to milk and misrepresent its store brand quality. Because consumers only observe quality after consumption, the one period lag gives room for the retailer to cheat concerning its store brand quality. By definition of a steady state equilibrium fulfilling consumers' expectations, the quality consumers anticipate is $q_{S}{ }^{*}$ as stated in equation (10), sold at price $p_{S}{ }^{*}$ from equation (11). Therefore the retailer can produce a poor-quality store brand at very low cost and sell it at price $p_{S}{ }^{*}$ during the first period. During the second period, no consumers will buy the store brand again but some of them will consume the national brand. ${ }^{12}$ There is therefore a gain for the retailer by cheating as it benefits from the first period private label discrimination revenues without incurring any cost. There is then a second period loss because demand for the private label drops to zero.

Profit in this third equilibrium is given by the following expression in prices when reputation is sustained for period 1, as stated in equation (11), and where the branded product price at period 2 is denoted $\tilde{p}_{S}$ :

$$
\begin{gathered}
\tilde{\Pi}(c)=\left(p_{B}^{*}-\frac{1}{2}\right) \cdot D_{B}\left(p_{B}{ }^{*}, p_{S}{ }^{*}(c), q_{S}{ }^{*}(c)\right)+\left(p_{S}^{*}-0\right) \cdot D_{S}\left(p_{B}{ }^{*}, p_{S}{ }^{*}(c), q_{S}{ }^{*}(c)\right) \\
+\Delta\left(\tilde{p}_{S}-\frac{1}{2}\right) \cdot D_{B}\left(\tilde{p}_{S}\right)-F
\end{gathered}
$$

The optimal price for the national brand in the second period is thus $\tilde{p}_{S}=\frac{3}{4}$ leading to a profit, when milking, equal to:

$$
\tilde{\Pi}(c)=\frac{1}{128}\left(27 c^{2}+8 \Delta-\sqrt{(9 c-8) c}\right)-F
$$

\section{The retailer's choice}

The retailer's choice over the three possible equilibria will rely on the three parameters of the model: $c, F$ and $\Delta$.

\footnotetext{
${ }^{12}$ It could have been assumed that consumers cheated on the store brand retaliate against the retailer by not consuming its branded product again. Under such an assumption, these consumers' demand would vanish. However, assuming that cheated consumers do not just vanish but that some of them consume the national brand in the second period does not qualitatively change our results.
} 
Proposition 1 : The less-frequently purchased is the product (the lower is $\Delta$ ) or the more brand-loyal consumers are (the higher is F), the harder it is to introduce a reputable private label.

Production cost at the same level as the national brand (i.e. $c=1$ ) is not a sufficient condition to ensure a reputable private label, nor introduction of a private label good.

\section{Proof :}

The retailer will prefer to sell the private label product and sustain its store brand reputation rather than selling only the national brand product as long as:

$\Pi_{B+S}{ }^{*}(c)>\Pi_{B}^{*} \Leftrightarrow \Delta>\Delta^{*}(c, F)=\frac{1-c+16 F+18 c(3 c-4) F+2 \sqrt{c}(9 c-8)^{\frac{3}{2}} F}{c-1}(15)$

For $\mathrm{c}=1$, this frontier can be prolonged by continuity: $\Delta^{*}(c, F) \stackrel{c \rightarrow 1}{\longrightarrow} \Delta^{*}(1, F)$ applying the L'Hospital rule, leading to $\Delta^{*}(1, F)=64 F-1$.

The retailer prefers to introduce a reputable store brand rather than cheating if and only if:

$$
\Pi_{B+S}{ }^{*}(c)>\tilde{\Pi}(c) \Leftrightarrow \Delta>\tilde{\Delta}(c)=\frac{4 \sqrt{c}}{\sqrt{9 c-8}+\sqrt{c}}(16)
$$

Because of continuity in profits and transitivity, comparing the trade-off between selling only the branded product and milking is not necessary.

Figure 1 depicts the optimal equilibrium for the retailer for its store brand introduction policy, illustrated with $F=0.02$.

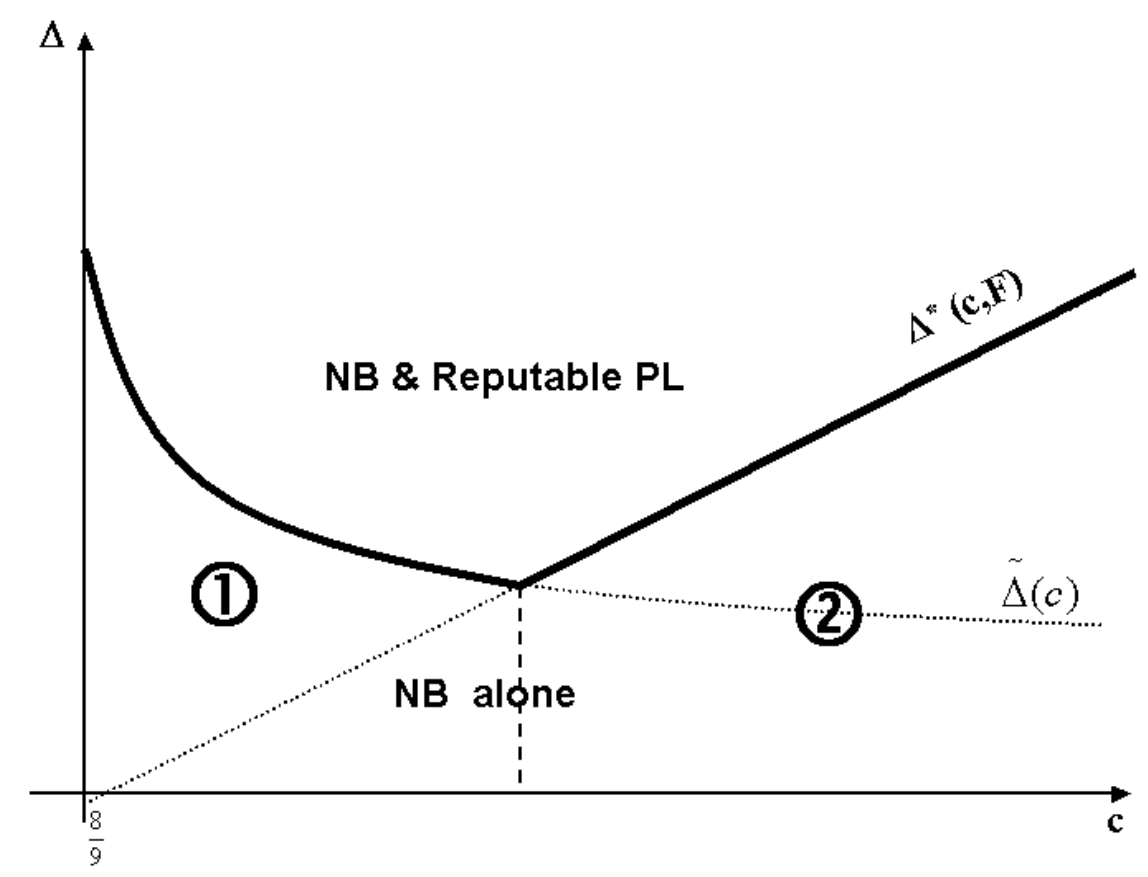




\section{Figure 1 : Introduction of the store brand, with $\mathbf{F}=\mathbf{0 . 0 2}$}

One interesting trade-off for the retailer is that between maintaining the reputation of its private label and using its reputation to milk consumers. It calls for two comments. The first is that the less patient is the retailer (the less frequently the product is purchased), the less credible is the store brand. Intuitively, an impatient retailer cares more about present profits than future ones. Therefore, its trade-off puts more weight on the gains from cheating (production costs saved) than on the future losses (foregone discrimination profits). The second comment, perhaps less intuitive, is that for a given discount factor, a decrease in $c$ increases the incentive for the retailer to milk. The frontier $\tilde{\Delta}$ is indeed decreasing in $c$. When $c$ is lower, that is when the national brand product has a

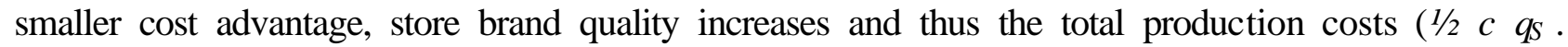
$D_{S}$ ) are also high. Gains from milking therefore increase as the saving of potential production is cost higher. Besides, as quality of the own brand product becomes closer to the one of the branded good, discrimination profits decrease. Therefore, the loss for the retailer to milk - that is the absence of the private label product in the second period - becomes less and less important.

Note that allowing the private label to have a slight advantage on the branded product $(c<1)$ does not qualitatively change the results.

The effect of considering the store brand as an experience good and not as a search good makes a difference. Without it, zone (1) would not exist. Indeed, in this zone, the retailer cannot sustain its reputation for its store brand. Because consumers anticipate that milking is more profitable for the distributor than sustaining reputation, they do not buy the store brand. The new product is not credible for consumers and the retailer only effectively sells the national brand. By contrast with zone (2) where the store brand is not introduced because the fixed cost is too high compared to the revenues generated by the new product, zone (1) deters the private label introduction because of the experience dimension of the good.

A decrease in the cost of private label goods is not sufficient to explain their introduction by retailers, because below a certain threshold, the store brand is not credible anymore. The next section takes into account the bargaining power parameter of the retailer for analysing the determinants of store brand introduction.

\section{Adding the retailer's bargaining power}

In order to incorporate retailer bargaining power into the model in a straightforward manner, we assume that the national brand manufacturer is also the private label manufacturer. Dobson (1998) and Dunne and Narasimahn (1999) give some examples where this is the case. One consequence of this assumption is that the retailer's bargaining power will be used to split profit both on the national brand product and on the store brand product since the manufacturer is the 
same for both goods. As a consequence of the national manufacturer also producing the private label, there is no cost disadvantage for the store brand product. Hence, $c=1$, and the unit cost of the private label production is therefore $\frac{1}{2} q_{S}{ }^{2}$. As is well known, having a two-part tariff between the distributor and the producer means the wholesale price is set to unit cost (that is: $w_{B}=1 / 2$ and $w_{S}=1 / 2$ $q_{S}{ }^{2}$ ) and the ex-post profit is divided according to the retailer's bargaining power parameter $\alpha{ }^{13}$ However, because of reputation effects, the national brand manufacturer would not be keen to produce a very low quality store brand in order to assist the retailer's milking strategy. If the retailer decides to milk, we assume he therefore turns to an independent firm from the competitive fringe to produce the zero-quality store brand. In the milking equilibrium, parameter $\alpha$ thus only applies to the national brand revenues but not to the store brand ones.

Proposition 2: The greater is the retailer bargaining power, the more likely is the introduction of a reputable private label.

\section{Proof :}

The ex-post profits in the three possible equilibria - equations (7), (12) and (14) - taking into account the bargaining framework with $c=1$, now become:

$$
\begin{gathered}
\Pi_{B}{ }^{*}=\alpha \cdot \frac{1+\Delta}{16} \\
\Pi_{B+S}{ }^{*}=\frac{5 \alpha(1+\Delta)}{64}-F
\end{gathered}
$$

and

$$
\begin{aligned}
\tilde{\Pi}(\alpha) & =\alpha\left(p_{B}{ }^{*}-\frac{1}{2}\right) \cdot D_{B}\left(p_{B}{ }^{*}, p_{S}{ }^{*}(1), q_{S}{ }^{*}(1)\right)+\left(p_{S}{ }^{*}-0\right) \cdot D_{S}\left(p_{B}{ }^{*}, p_{S}{ }^{*}(1), q_{S}{ }^{*}(1)\right) \\
& +\alpha . \Delta\left(\tilde{p}_{S}-\frac{1}{2}\right) \cdot D_{B}\left(\tilde{p}_{S}\right)-F \\
& =\frac{1}{64}(5+\alpha(2+4 \Delta))-F
\end{aligned}
$$

respectively. The two frontiers $\Delta(\alpha)$ and $\tilde{\Delta}(\alpha)$ thus become:

$$
\begin{aligned}
& \Pi_{B}^{*}=\Pi_{B+S}{ }^{*}(\alpha) \Leftrightarrow \Delta^{*}(\alpha)=\frac{64 F}{\alpha}+1 \\
& \tilde{\Pi}(\alpha)=\Pi_{B+S}(\alpha) \Leftrightarrow \tilde{\Delta}(\alpha)=\frac{5}{\alpha}-3
\end{aligned}
$$

\footnotetext{
13 The Nash-Bargaining framework, detailed in Osborne and Rubinstein (1990), leads to a retailer's ex-post profit equal to $\alpha \%$ of the vertical structure profits, whereas the manufacturer gets $(1-\alpha) \%$ of it. The wholesale price maximizes the vertical structure profits (joint profits) whereas the franchise fee (not modelled here) allocates the surplus between the agents according to their bargaining power.
} 
The new situation is depicted in Figure 2.

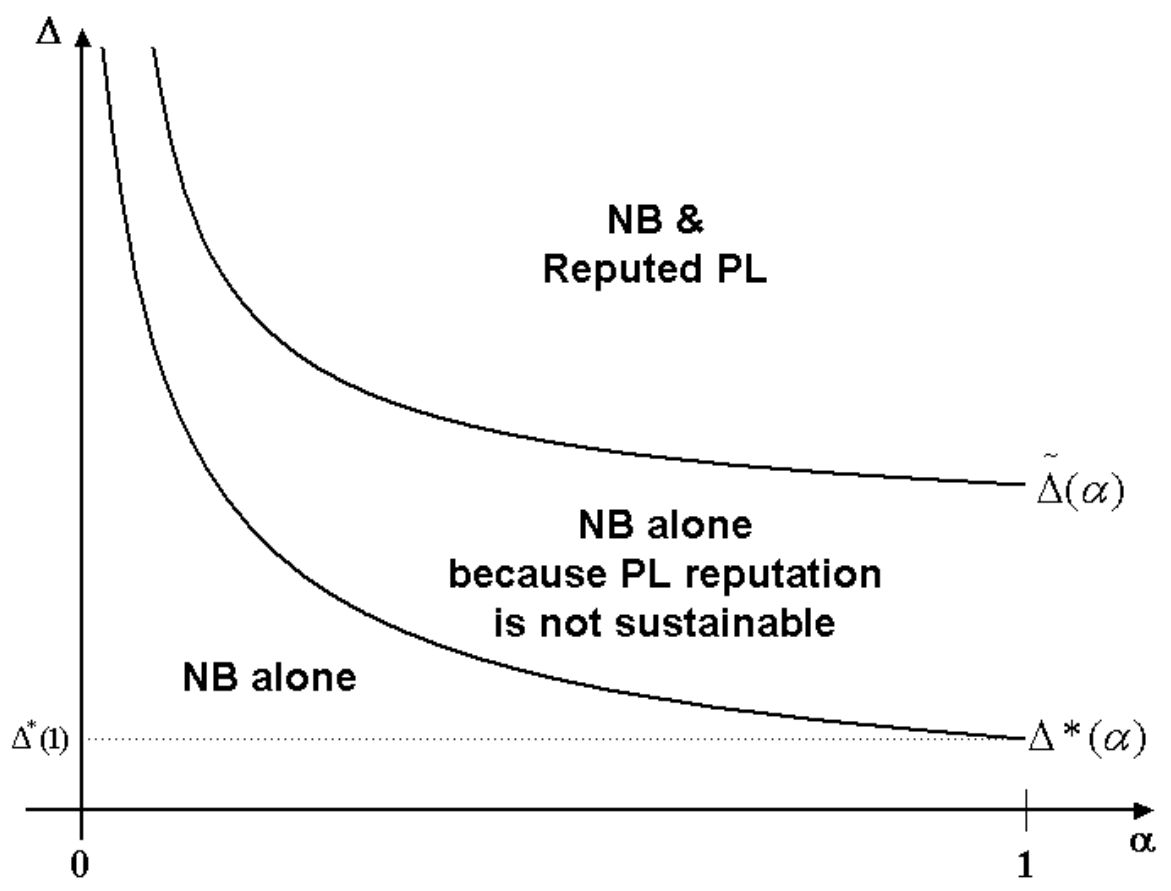

Figure 2: Introduction of the store brand wi th the retailer's bargaining power, with $\mathrm{F}=\mathbf{0 . 0 2}$

An increase in bargaining power has two effects on the milking reputation for the retailer. First, it obviously makes the introduction of the store brand more likely by giving the retailer more profit with which to cover the fixed cost $F$ associated with the introduction of the new product. The second effect concerns reputation: when $\alpha$ increases, the ex-post foregone profits of discrimination when the retailer milks also increase. This lowers the incentives for the retailer to cheat on store brand quality.

It is also interesting to note that, even if the bargaining power increases, so long as the frequency of purchase of the product is quite low $(\Delta<\tilde{\Delta}(1))$, producing a high quality private label is not a credible strategy.

The recent mergers within the retailing industry can be reinterpreted as an increase of the retailer's bargaining power vis-à-vis the manufacturer. In our model, this translates into a greater likelihood of the store brand being introduced because the benefits of reputation become more important.

\section{Conclusion}

The first general result of the paper is that considering the private label as an experience good has a significant impact on the outcome. Indeed, for products characterised by a low frequency of purchase, a private label is not credible and the retailer cannot maintain his reputation. 
In addition, the decreasing marginal cost disadvantage of the private label production is not always sufficient to ensure that the private label will be introduced.

Consideration of the retailer's bargaining power can jeopardise the decision to introduce a private label. When the retailer bargaining power is high enough, it gives the distributor incentives to maintain its reputation by making the losses in case of milking too high. As previously, if the good is characterised by a low frequency of purchase, a high bargaining power is not sufficient to insure private label introduction. There is indeed a threshold under which a reputable brand is not viable.

These conclusions can give some insight into why, for some products such as Hot Beverages or Health \& Beauty (goods with low frequency of purchase compared to groceries), retailers' private label have a rather small market share (24.4\% in average). Of course, reputation is not the only factor in explaining the market share of the own-brand product because investment in brand and product image (advertising) are also important. In our model, we focussed on the reputation effect. Such an effect in not present when considering a private label as a search good because consumers have all the information and only look for the best 'quality/price' value.

In order to simplify the analysis, downstream competition is not modelled in this paper. In fact, introducing downstream competition will give consumers the opportunity to buy at another retailer's shop if they anticipate the retailer will milk. In the second period, the retailer will therefore earn zero profits rather than some profit due to the captive demand on the branded product. This implies that the presence of downstream competition will lessen the incentives retailers have to milk, but not remove them. 


\section{REFERENCES}

Allen F. (1984), "Reputation and product quality", RAND Journal of Economics, 15(3), p. 311-327;

Bergès-Sennou F. , Bontems P. and Réquillart V. (2003), "Economic Impact of Private Labels Invasion", INRA Working Paper, 21 pages;

Bontems P. , Monier S. and Réquillart V. (1999), "Strategic effects of private labels", European Review of Agricultural Economics, 26(2), p. 147-165;

Caprice S. (2000), Contributions à l'analyse de la puissance d'achat dans les relations verticales : Intéractions stratégiques et marques de distributeurs, Thèse pour le Doctorat en Sciences Economiques, Université PARIS I, s/d de Anne PERROT;

Clarke R., Davies S., Dobson P. and Waterson M. (2002), Buyer Power and Competition in European Food Retailing, Edward Elgar Publishing, ISBN 1-84064-685-3, 203 pages;

Dobson P. (1998), "The economic welfare implications of own-labelled good", mimeo, University of Nottingham, 47 pages;

Dunne D. \& Narasimhan C. (1999), "The new appeal of private label", Harvard Business Review, May-June 1999, p. 41-52;

Mills D. (1995), "Why retailers sell private labels", Journal of Economics \& Management Strategy, 4(3), p. 509-528;

Mussa M. \& Rosen S. (1978), "Monopoly and Product Quality", Journal of Economic Theory, 18, p. $301-317$;

Nelson P. (1970), "Information and Consumer Behavior", Journal of Political Economy, 78(2), p. 311-329;

Osborne M. \& Rubinstein A. (1990), Bargaining and Markets, Academic Press, ISBN 0-12528632-5, 211 pages ;

PLMA (2002), International Private Label Yearbook: "A statistical guide to market share trends", Private Label Manufacturers Association and AC Nielsen, http: / /www.plma.com; 
Rao A. and K. Monroe (1989), “The Effect of Price, Brand Name, and Store Name on Buyers' Perceptions of Product Quality: An Integrative Review", Journal of Marketing Research, XXVI, p. 351-357;

Richardson P., A. Dick and A. Jain (1994), "Extrinsic and Intrinsic Cue Effects on Perceptions of Store Brand Quality", Journal of Marketing, 58, p. 28-36;

Shapiro C. (1983), "Premiums for high quality products as returns to reputations", Quarterly Journal of Economics, 98(4), p. 659-679;

Shapiro C. (1982), "Consumer information, product quality, and seller reputation", Bell Journal of Economics, 13, p.20-35;

Shapiro E. (1993), "Price Lure of Private-Label Products Fails to Hook Many Buyers of Baby Food and Beer", The Wall Street Journal, May $13^{\text {rd }}$ of 1993, p. B1;

Tirole J. (1988), The Theory of Industrial Organization, Cambridge, The MIT Press; 